\title{
Tetralogy of Fallot with anomalous pulmonary venous connections: a rare but clinically important association
}

\author{
Andrew N Redington, Joseph Raine, Elliot A Shinebourne, Michael L Rigby
}

\begin{abstract}
Anomalous pulmonary venous connections were found in seven $(0.6 \%)$ of 1183 patients with tetralogy of Fallot. Three patients had totally anomalous connections (one supracardiac, one direct to coronary sinus, and one mixed supracardiac and infracardiac) and four patients had partially anomalous pulmonary venous connections. All patients presented with the clinical features of tetralogy of Fallot. Anomalous pulmonary venous drainage was suspected clinically in only one patient in whom there was a scimitar sign on the chest radiograph. The exact diagnosis was established by cross sectional echocardiography (one), preoperative or postoperative angiography (five), or at necropsy (one). Surgery was performed in six patients. Total correction without re-routing of the anomalously draining veins was successful in all those with partially anomalous connections, with no significant long term sequelae (follow up median 17 years). Of those with totally anomalous connections, the full diagnosis was made only at necropsy in one patient, successful one-stage correction was performed in one, and the other patient, who had partially obstructed mixed drainage, died shortly after one-stage correction. Histological examination of the lung biopsy specimen in this patient showed grade 2 pulmonary vascular disease.

Tetralogy of Fallot with anomalous pulmonary venous connections is a rare association. Careful preoperative assessment is required in those with totally anomalous connections.
\end{abstract}

There are scattered reports describing the association of tetralogy of Fallot with totally anomalous pulmonary venous connections. ${ }^{1-3}$ With fewer than 10 published cases this is an infrequent association that is rarely suspected clinically. Its diagnosis by cross sectional echocardiography has not been reported, but the complete diagnosis has been made at the time of cardiac catheterisation, ${ }^{4}$ corrective surgery, ${ }^{5}$ or necropsy. ${ }^{6}$ Furthermore, there are few data on the incidence and association of tetralogy of Fallot with partially anomalous pulmonary venous connections. ${ }^{1}$ We reviewed all cases of tetralogy of Fallot with anomalous pulmonary venous connections seen at the Brompton and National Heart Hospitals in the past 20 years.

\section{Patients and methods}

We reviewed the records of 1183 patients with a diagnosis of tetralogy of Fallot investigated at the Brompton and National Heart Hospitals in the past 20 years. Only patients with atrial situs solitus were reviewed; we excluded those with isomerism of the atrial appendages.

Seven patients $(0.6 \%)$ had abnormalities of pulmonary venous connection. Their ages at presentation ranged from three days to four months. In only one was the complete diagnosis made by cross sectional echocardiography. In the remainder the diagnosis was made either at the time of cardiac catheterisation (four patients), corrective surgery and later cardiac catheterisation (one), or at necropsy (one).

\section{Case reports}

The table gives the clinical data, full sequential diagnosis, and outcome for each of the seven patients.

\section{THREE CASES OF TETRALOGY OF FALLOT WITH TOTALLY ANOMALOUS PULMONARY VENOUS CONNECTION}

Case 1

A 3 year old boy, cyanosed from early infancy, was referred after cardiac catheterisation elsewhere. The cineangiograms confirmed the presence of tetralogy of Fallot with severe obstruction of the right ventricular outflow tract caused by anterior deviation of the outlet septum and stenosis of the pulmonary valve. Selective injections into normal-sized right and left pulmonary arteries showed unsuspected mixed pulmonary venous connections, the right lower lobe and all the left sided pulmonary veins forming a confluence and draining infradiaphragmatically, and the right upper and middle pulmonary veins draining to the superior caval vein at its junction with the innominate vein (fig 1). Haemodynamic measurements showed that the pulmonary artery pressure was $45 / 22 \mathrm{~mm} \mathrm{Hg}$ with right and left ventricular pressures of $75 / 8 \mathrm{~mm} \mathbf{~ g}$. His aortic oxygen saturation was $73 \%$.

Complete correction of tetralogy of Fallot with anastomosis of the pulmonary venous confluence to the left atrium was performed. A stenosis of the insertion of the right upper and middle pulmonary veins into the superior 
Data on each of the seven patients

\begin{tabular}{|c|c|c|c|c|c|c|}
\hline Case & Sex & $\begin{array}{l}\text { Age at } \\
\text { presentation }\end{array}$ & Clinical features & Asscociated abnormalities & Operation & Outcome \\
\hline 1 & $\mathbf{M}$ & 4 months & Cyanosis and heart murmur & $\begin{array}{l}\text { Mixed supracardiac and } \\
\text { infracardiac TAPVC }\end{array}$ & One-stage correction age 4 & $\begin{array}{l}\text { Died after operation. Lung } \\
\text { histology showed grade } 2 \\
\text { pulmonary vascular disease }\end{array}$ \\
\hline 2 & $\mathbf{M}$ & 12 hours & $\begin{array}{l}\text { Dysmorphic features, } \\
\text { cyanosis, respiratory } \\
\text { distress, heart murmur }\end{array}$ & $\begin{array}{l}\text { Absent pulmonary valve } \\
\text { syndrome and TAPVC to } \\
\text { coronary sinus }\end{array}$ & Not performed & $\begin{array}{l}\text { Died of respiratory failure at } \\
30 \text { hours of age }\end{array}$ \\
\hline 3 & $\mathbf{M}$ & 3 days & Cyanosis and heart murmur & $\begin{array}{l}\text { Supracardiac TAPVC, left } \\
\text { vertical vein to innominate } \\
\text { vein }\end{array}$ & $\begin{array}{l}\text { One-stage correction age } 9 \\
\text { months }\end{array}$ & Well 9 months after operation \\
\hline 4 & $\mathbf{M}$ & 4 months & Cyanosis and heart murmur & $\begin{array}{l}\text { Scimitar syndrome. Right } \\
\text { hemianomalous drainage } \\
\text { to hepatic vein }\end{array}$ & $\begin{array}{l}\text { Correction of TOF age } 9 \\
\text { years }\end{array}$ & Well 1 year after operation \\
\hline 5 & $\mathbf{M}$ & 1 month & Cyanosis and heart murmur & $\begin{array}{l}\text { Right upper lobe vein to } \\
\text { SVC }\end{array}$ & $\begin{array}{l}\text { Blalock-Taussig shunt age } 3 \\
\text { months, correction of } \\
\text { TOF age } 18 \text { years }\end{array}$ & Well 17 years after operation \\
\hline 6 & $\mathrm{~F}$ & 4 months & Cyanosis and heart murmur & $\begin{array}{l}\text { Right upper lobe vein to } \\
\text { SVC }\end{array}$ & $\begin{array}{l}\text { Waterston shunt age } 7 \text { years, } \\
\text { correction of TOF age } 9 \\
\text { years }\end{array}$ & Well 17 years after operation \\
\hline 7 & $\mathbf{F}$ & 2 months & $\begin{array}{l}\text { Cyanosis, heart murmur, and } \\
\text { respiratory tract infections }\end{array}$ & $\begin{array}{l}\text { Right upper and middle lobe } \\
\text { veins to SVC }\end{array}$ & $\begin{array}{l}\text { Correction of TOF age } 10 \\
\text { years }\end{array}$ & $\begin{array}{l}\text { Short of breath on exertion } 26 \\
\text { years after operation }\end{array}$ \\
\hline
\end{tabular}

TOF, tetralogy of Fallot; APVC, anomalous pulmonary venous connections; TAPVC, total anomalous pulmonary venous connections; SVC, superior vena cava.

caval vein was relieved by a patch but these veins were left to drain anomalously. The immediate postoperative course was complicated by severe recurrent and refractory pulmonary hypertensive crises. He died four hours after operation.

Necropsy confirmed a satisfactory surgical repair but histological examination of the lung parenchyma showed Heath-Edwards grade II pulmonary vascular disease with a considerable increase in arteriolar wall smooth muscle. There was no intimal hyperplasia or vessel obliteration.

Case 2

A full term baby (birth weight $2.9 \mathrm{~kg}$ ) was born with multiple dysmorphic features including low-set ears, flat nose, absent left thumb, and a rudimentary fifth ulnar digit. $\mathrm{He}$ was referred at 12 hours of age because of severe cyanosis. He had been intubated and ventilated because of increasing respiratory distress and severe cyanosis $\left(\mathrm{po}_{2}=3.1 \mathrm{kPa}\right.$ in $50^{\circ}$ inspired oxygen) despite infusion of prostaglandin $\mathrm{E}_{2}$. The chest radiograph showed a normal heart size, pulmonary oligaemia, and hyperinflation of the left lung with mediastinal shift towards the right. Cross sectional echocardiography showed abdominal situs solitus, with a concordant atrio- ventricular connection. There was tetralogy of Fallot with features typical of absent pulmonary valve syndrome. There was severe infundibular stenosis and very large confluent main, right, and left pulmonary arteries. The pulmonary venous drainage was not clearly displayed.

There was rapid deterioration in the child's condition with gross obstuctive emphysema of both lungs. It was thought that surgical correction was inappropriate in view of his poor condition, severe respiratory symptoms, and probable chromosomal disorder and he died at 30 hours of age. Necropsy confirmed the underlying diagnosis of tetralogy of Fallot with absent pulmonary valve syndrome and also showed totally anomalous pulmonary venous connection to the coronary sinus. The pulmonary veins were small. Subsequent chromosomal analysis showed a deletion on chromosome 15 with a mosaic loss of the $Y$ chromosome.

\section{Case 3}

A 3 day old neonate was referred because of persistent cyanosis. The clinical findings were compatible with isolated tetralogy of Fallot.

Cross sectional echocardiography showed features typical of tetralogy of Fallot. There was, in addition, supracardiac totally
Figure 1 Selective pulmonary arteriogram $(A)$ and laevophase examination $(B)$ from patient 1. There was a mixed totally anomalous pulmonary venous connection. The pulmonary veins from the right upper and middle lobes drained directly to the superior vena cava. The right lower lobe vein drained to form a confluence with the veins from the left lung which drained infradiaphragmatically via a common vein. $P A$ pulmonary artery; $P V C$, pulmonary venous connection.
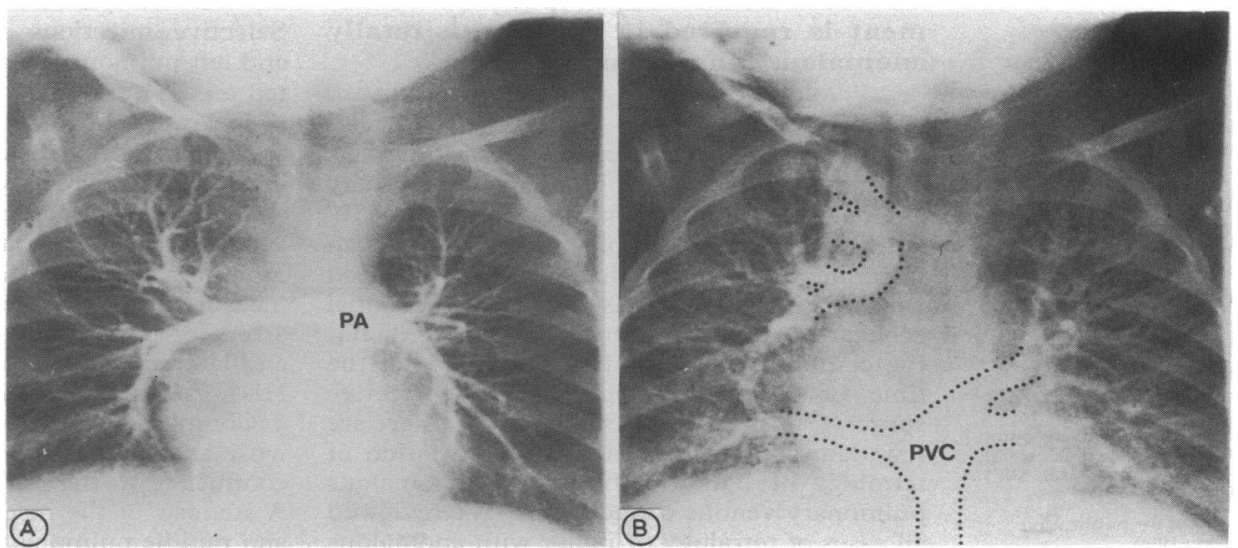
Figure 2 Cross sectional echocardiograms from patient 3. The subcostal 4 chamber section $(A)$ shows the pulmonary venous confluence (pvc) outside the left atrium

( $L A)$. The suprasternal paracoronal section $(B)$ shows the left vertical vein $(V V)$ draining to the innominate vein. $R A$, right atrium, $L V$, left ventricle; $R V$, right ventricle.
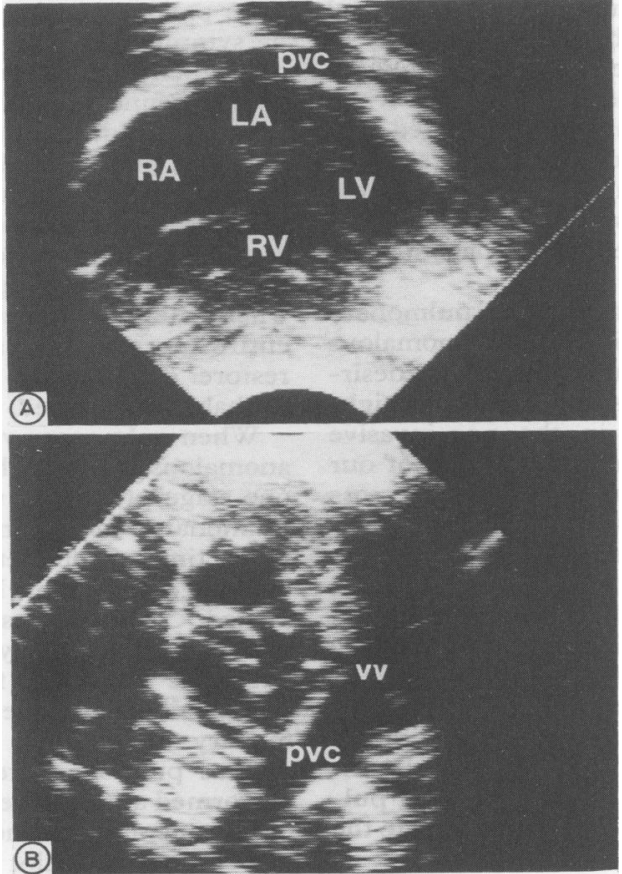

anomalous pulmonary venous connection with the pulmonary venous confluence draining via a left sided vertical vein to the left innominate vein (fig 2 ). Phasic but low velocity flow was shown in the pulmonary veins by Doppler interrogation.

He remained moderately cyanosed but was otherwise well. Cardiac catheterisation was performed when he was nine months old to confirm that he was suitable for complete correction. Surgery was performed elsewhere when he was 10 months old. His early postoperative course was complicated by low cardiac output and bilateral pleural effusions which resolved during the first postoperative week. He has subsequently made a full recovery and is now symptom free nine months after operation.

\section{TETRALOGY OF FALLOT WITH PARTIALLY}

ANOMALOUS PULMONARY VENOUS CONNECTIONS All of the patients in this group presented with cyanosis in the first four months of life and had cardiac catheterisation before complete correc- tion. Cross sectional echocardiography was performed before correction in only one patient (the others having been investigated before the introduction of the technique). In this case there was a hypoplastic right lung on the chest radiograph and no pulmonary veins that drained normally from the right lung could be shown by cross sectional echocardiography. Subsequent cardiac catheterisation with angiography showed a scimitar syndrome, with the pulmonary venous return from the hypoplastic right lung draining infradiaphragmatically to a hepatic vein. The right pulmonary artery was hypoplastic. The arterial blood supply to the right lower lobe was from an artery arising from the descending aorta (fig 3 ). The presence of anomalous venous drainage was noted in one other patient before operation (right upper lobe pulmonary vein to superior caval vein (patient 6 ). This patient made an uncomplicated recovery after a Waterston shunt performed at the age of seven years. In patient 7 anomalous drainage of right middle and upper lobe veins to the junction of the right superior caval and azygous veins was detected during a corrective operation. In patient 5 a right upper lobe vein draining to the right superior vena cava was shown only at routine postoperative cardiac catheterisation.

All of these patients have undergone successful complete correction of tetralogy of Fallot. There was no attempt to re-route the anomalous pulmonary veins in any of the patients. Follow up ranges from five months to 26 years (median 17 years). All are leading normal lives and three are entirely symptom free. One patient is short of breath on vigorous exertion (case 7). This patient was found to have an atrial septal defect of moderate size and residual obstruction of right ventricular outflow tract that required further operation. This was performed 23 years after the original repair; again no attempt was made to re-route the anomalous pulmonary veins.

\section{Discussion}

This study describes the clinical features and outcome of seven patients with tetralogy of Fallot and anomalous pulmonary venous connections. This was an uncommon association that occurred in $0.6 \%$ of the patients with tetralogy of Fallot seen at our hospitals in the past 20 years.
Figure 3 Selective right pulmonary arteriogram ( $R P A$ ) from the patient with scimitar syndrome (A). Hemianomalous pulmonary venous drainage $(P V)$ of the right lung

infradiaphragmatically to the hepatic vein $(B)$. An angiogram of the

descending aorta $(C)$. The systemic blood supply to the right lower lobe was abnormal (arrow).
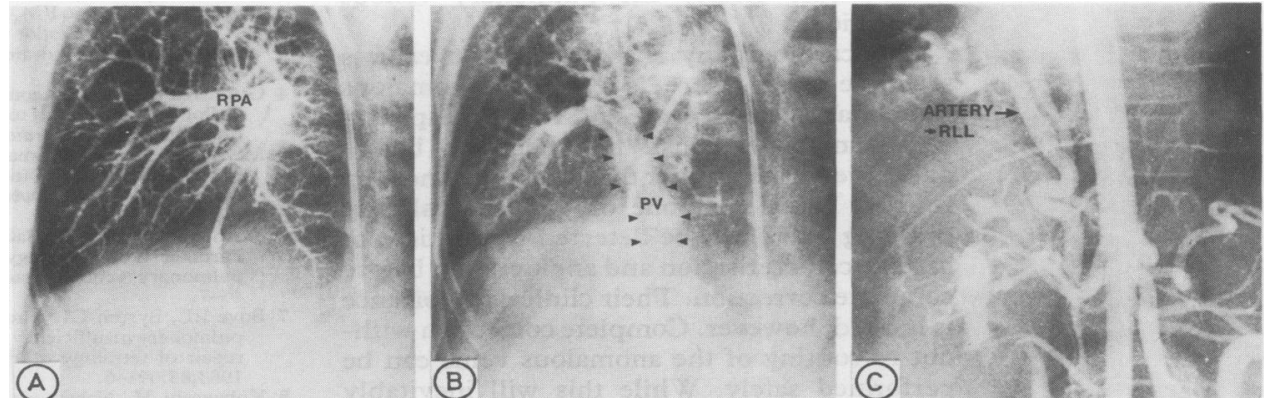
All of the patients presented with clinical features compatible with isolated tetralogy of Fallot. This is because reduced pulmonary blood flow is the dominant lesion, even when pulmonary venous return is obstructed. ${ }^{1}$ In only one patient, in whom there was a hypoplastic right lung and a scimitar vein on the chest radiograph, was the possibility of anomalous pulmonary venous drainage suspected clinically.

When there is totally anomalous pulmonary venous drainage early diagnosis of anomalous pulmonary venous return is particularly desirable, although previous reports have highlighted the difficulties in the non-invasive diagnosis of this association. ${ }^{26}$ In one of our patients the diagnosis was established by cross sectional echocardiography, a pulmonary venous confluence and vertical vein draining to the innominate vein being shown clearly. However, cross sectional echocardiography in our patient with coexisting absent pulmonary valve syndrome did not show totally anomalous pulmonary venous connection to the coronary sinus. This patient died from severe respiratory complications and at necropsy very small pulmonary veins, again reflecting decreased pulmonary blood flow, were seen connecting to the coronary sinus.

This combination of anomalies thus represents a considerable diagnostic challenge to the clinician. There are considerable practical implications to the diagnosis. It would clearly be undesirable to perform palliative surgery to increase pulmonary blood flow if the pulmonary venous return was obstructed. Muster and coworkers described just such a case, in which fatal intractable pulmonary oedema developed after a Potts anastomosis, there being only a $1.5 \mathrm{~mm}$ aortopulmonary anastomosis at subsequent necropsy. ${ }^{1}$ Despite a clinical picture of reduced pulmonary blood flow, important changes in pulmonary vasculature developed in our three year old patient with partially obstructed mixed drainage. This patient was referred from another hospital and no formal measurements of pulmonary vascular resistance had been made. None the less raised pulmonary artery diastolic pressure should raise the possibility of pulmonary vascular disease in such a patient. It would be impractical for all patients with tetralogy of Fallot to have cardiac catheterisation before palliative surgery, however. We suggest that angiography should be considered in patients when cross sectional echocardiography fails to demonstrate clearly the pulmonary venous connections.

Echocardiography is likely to be even less sensitive when there is partially anomalous pulmonary venous drainage. It is perhaps less important to establish the diagnosis before palliative surgery under these circumstances. It is more likely that one or two anomalously draining veins will be detected at the time of cardiac catheterisation and angiography before complete correction. Their clinical importance is limited, however. Complete correction without re-routing of the anomalous veins can be performed safely. While this will inevitably result in a degree of excess volume load to the right ventricle, the long term follow up in our older patients suggests that this has little effect on symptoms or functional state. Only one of our patients had a hemianomalous pulmonary venous connection (case 4 ). This patient had a scimitar syndrome with a hypoplastic right lung and pulmonary artery. Pulmonary blood flow and hence venous return was limited and so correction of tetralogy of Fallot without rerouting of the anomalous pulmonary veins was thought to be appropriate. In other patients where the pulmonary venous return from an entire lung may drain anomalously, attempts to restore drainage to the left atrium should probably be pursued.

When pulmonary venous drainage is totally anomalous it should be possible to perform a one-stage procedure with anastomosis of the pulmonary venous confluence to the left atrium at the time of complete correction. Successful one-stage correction has been previously reported $^{578}$ and the postoperative course in our patient was relatively uncomplicated. If the patient is unsuitable for complete correction, but requires palliative surgery to increase pulmonary blood flow, correction of the anomalous pulmonary venous return should be performed at the same time because of the risk of postoperative pulmonary oedema. ${ }^{1}$

Tetralogy of Fallot is rarely associated with anomalous pulmonary venous connection. The diagnosis is rarely suspected clinically because the reduction of pulmonary blood flow dominates the clinical presentation. The diagnosis may be made by cross sectional echocardiography, but angiography should be considered if normal pulmonary venous drainage cannot clearly be shown by non-invasive techniques. Complete correction with anastomosis of the pulmonary venous confluence to the left atrium is best performed within the first year of life if pulmonary venous connection is totally anomalous, particularly if there is any evidence of pulmonary venous obstruction. Correction of tetralogy of Fallot without re-routing of anomalously draining veins can be performed without serious long term sequelae if only one or two lobar vessels are affected.

We thank Dr J Somerville, National Heart Hospital, London, and Professor G Falkowski, Bakulev Institute, Moscow, for supplying details of patients under their care. We also thank D National Heart and Lung Institute for examining the necropsy specimens.

1 Muster AJ, Paul MH, Nikaidoh H. Tetralogy of Fallot associated with total anomalous pulmonary venous drainassociated with total anom
age. Chest 1973;64:323-6.

2 Gerlis IM, Fiddler GI, Pearse RG. Total anomalous pulmonary venous drainage associated with tetralogy of Fallot: report of a case. Pediatr Cardiol 1983;4:297-300.

3 Bonvicini M, Picchio FM, Baccarani G, Rapezzi C, Magnan B. Tetralogy of Fallot associated with total anomalous pulmonary venous drainage. Case report. G Ital Cardiol 1980;10:1538-45.

4 Gutierrez J, Perez de Leon J, de Marco E, et al. Tetralogy of Fallot associated with total anomalous pulmonary venous drainage. Pediatr Cardiol 1983;4:293-6.

5 Miyamoto K, Kawashima Y, Mori T, et al. Pentalogy of Fallot associated with total anomolous pulmonary venous drainage. Nippon Kyobu Geka Gakkai Zasshi 1979;27:

6 Khandeparkar JMS, Balkrishnan KR, Tendolkar AG Parulkar GB. Pentalogy of Fallot with total anomalous pulmonary venous drainage. J Postgrad Med 1987;33:

7 Bove EL, Byrum CJ, Thomas FD, et al. The influence of pulmonary insufficiency on ventricular function following repair of tetralogy of Fallot. $J$ Thorac Cardiovasc Surg 1983;85:691-6.

8 Kobayashi H, Nakamura T, Sagara T, et al. Successful repair of tetralogy of Fallot associated with tota anomalous pulmonary venous drainage. Kyobu Geka 1978;31:935-7. 